\title{
PENGEMBANGAN LEMBAR KERJA SISWA (LKS) PADA MATERI HUKUM ARCHIMEDES DENGAN MENGGUNAKAN MODEL PEMBELAJARAN PROBLEM BASED LEARNING
}

\author{
Shella Rizki Yuliana, Patricia H.M Lubis, Sugiarti \\ Program Studi Pendidikan Fisika. Universitas PGRI Palembang \\ Email: shellarizkiyuliana12@gmail.com
}

Diterima: 18 Desember 2020. Direvisi: 18 Maret 2021. Disetujui: 20 Maret 2021.

\begin{abstract}
Abstrak
Penelitian ini bertujuan untuk mengembangkan Lembar Kerja Siswa (LKS) materi hukum Archimedes dengan menggunakan Model Pembelajaran Berbasis Masalah Valid dan Praktis. di SMA Pembina Palembang. Sampel pada penelitian ini adalah siswa kelas XI IPA 2 Motode penelitian yang digunakan yaitu penelitian dan pengembangan (Research \& Davelopment). Teknik pengumpulan data menggunakan walkthrough, wawancara, dan angket. Teknik analisis pengambilan data yang digunakan adalah validasi, one to one, dan small group. Hasil penelitian menunjukkan bahwa pengembangan lembar kerja siswa (LKS) pada materi hukum archimedes dengan menggunakan model pembelajaran problem based learning di SMA Pembina Palembang Tahun Ajaran 2020/2021 adalah LKS yang dilakukan pada kategori valid dengan hasil total 4,38 termasuk dalam kategori valid. Pada tahap One to one diperoleh hasil total dengan skor 0,70 termasuk dalam kategori Praktis dan pada tahap Small group diperoleh hasil total dengan skor 0,69 termasuk dalam kategori Praktis.
\end{abstract}

Kata Kunci: Lembar Kerja Siswa, Archimedes, Problem Based Learning.

\begin{abstract}
The problem in this research is how to develop Student Worksheets (LKS) on Archimedes law material by using a Valid and Practical Problem Based Learning Model at SMA Pembina Palembang. The sample in this study were students of class XI IPA 2. The research method used was research and development (Research \& Development). The data technique used a walkthrough, interview, and questionnaire. The data analysis techniques used were validation, one to one, and small group. The results showed that the development of student worksheets (lks) on archimedes legal material using a problem-based learning model at SMA Pembina Palembang for the 2020/2021 academic year, namely Student Worksheets (LKS) developed in the valid category with a total result of 4.38 included in very valid category. In the practicality category, the total results obtained with a score of 23.29 are included in the very practical category.
\end{abstract}

Keywords: Student Worksheets, Archimedes, Problem Based Learning.

\section{PENDAHULUAN}

Pembelajaran adalah suatu usaha dimana seseorang mendapatkan ilmu dan pengaruh yang positif dari yang tidak tahu menjadi tahu. Berdasarkan dari pengetahuan tersebut seseorang dapat mengetahui mana hal yang 
Yuliana., Lubis., Sugiarti. - Pengembangan Lembar Kerja Siswa ...

positif untuk dijadikan motivasi perubahan yang lebih baik.

Pembelajaran adalah proses interaksi antara guru dan siswa, baik secara langsung maupun tidak langsung (Rusman, 2015). Pembelajaran adalah proses interaksi antara siswa dan guru beserta unsur yang ada dalam proses belajar mengajar (Yunita, 2016). Pembelajaran merupakan suatu usaha dari siswa dalam pemahaman materi, agar siswa dapat memecahkan masalah untuk mendapatkan hasil belajar yang memenuhi kriteria ketuntasan (Fatimah, Ertikanto, \& Suana, 2014). Pada hakikatnya pembelajaran dapat diterapkan dimana saja baik disekolah, dirumah maupun dilingkungan masyarakat. Berdasarkan pendapat diatas, dapat disimpulkan bahwa pembelajaran merupakan suatu usaha yang dapat mempengaruhi siswa untuk lebih aktif dalam proses belajar mengajar. Oleh karena itu pembelajaran sangatlah penting bagi setiap siswa yang ada dilingkungan sekolah maupun dimasyarakat, yang dilakukan antara guru dengan siswa dan sumber belajar.
Fisika merupakan salah satu pelajaran yang dipelajari siswa di sekolah, yang berkaitan dengan fenomena alam yang terjadi didalam kehidupan sehari-hari. Fisika termasuk mata pelajaran yang tidak hanya berisi teori dan hafalan, tetapi Fisika memerlukan proses terbentuknya pengetahuan melalui suatu penemuan dan penyajian data. Fisika adalah ilmu yang mempelajari tentang fenomena alam yang mempelajari materi, energi dan fenomena alam (Yolanda, Lubis, \& Sugiarti, 2020). Namun juga siswa diharapkan dapat memecahkan masalah pada pelajaran Fisika dan prinsip hukum Fisika, agar siswa memiliki pemahaman yang baik. Selain itu pelajaran Fisika lebih menuntut pemahaman konsep serta penerapan aplikasi dalam kehidupan sehari-hari (Purwanto, 2012).

Kesuksesan siswa dalam memecahkan suatu masalah Fisika, merupakan tugas utama yang dilakukan seorang pendidik yang melatih siswanya berfikir kreatif dan logis. Salah satu yang dapat membantu untuk menerapkan perangkat pembelajaran yang sesuai 
Yuliana., Lubis., Sugiarti. - Pengembangan Lembar Kerja Siswa ...

untuk siswa yaitu Lembar Kerja Siswa (LKS). LKS adalah salah satu perangkat belajar siswa untuk mempermudah dalam proses belajar. LKS merupakan suatu media penunjang pembelajaran bagi siswa dan guru (Fatimah, Ertikanto, \& Suana, 2014). LKS adalah lembaran yang berisi soal-soal untuk dikerjakan oleh siswa, dan terdapat langkahlangkah dalam menyelesaikan soal tersebut.

Berdasarkan pendapat para ahli tersebut, dengan menggunakan LKS dapat membantu guru dan siswa dalam melakukan aktifitas belajar. LKS juga berfungsi sebagai media yang dapat menimbulkan aktifitas dalam proses belajar mengajar di dalam kelas. Selain itu agar dapat memecahkan masalah pada materi pelajaran Fisika dan dunia nyata, dengan menggunakan model pembelajaran problem based learning.

Dalam pembelajaran Fisika terdapat suatu model berbasis masalah salah satunya yaitu model pembelajaran problem based learning. Model pembelajaran problem based learning adalah penyelesaian suatu masalah yang terjadi pada siswa dalam proses belajar mengajar dikelas. Model problem based learning adalah suatu model pembelajaran yang menyajikan permasalahan kontekstual sehingga siswa merangsang dalam proses belajar melalui pengetahuan (Yoesoef, 2015). Model problem based learning merupakan model belajar yang menggunakan masalah untuk dipecahkan dalam mengumpulkan dan menemukan pengetahuan baru dalam belajar baik induvidu maupun berkalaborasi (Fatimah, Ertikanto, \& Suana, 2014).

Berdasarkan dari permasalahan yang ada, maka model yang cocok digunakan adalah model pembelajaran Problem Based Learning (PBL) untuk memudahkan siswa dalam memecahkan masalah. Model ini berfokus untuk meningkatan keaktifan siswa dalam melakukan kegiatan belajar agar terfokus dalam memecahkan masalah. Manfaat dari menggunakan model problem based learning adalah dapat memudahkan dan membantu siswa dalam memecahkan masalah yang ada kaitannya dalam Fisika. 
Yuliana., Lubis., Sugiarti. - Pengembangan Lembar Kerja Siswa ...

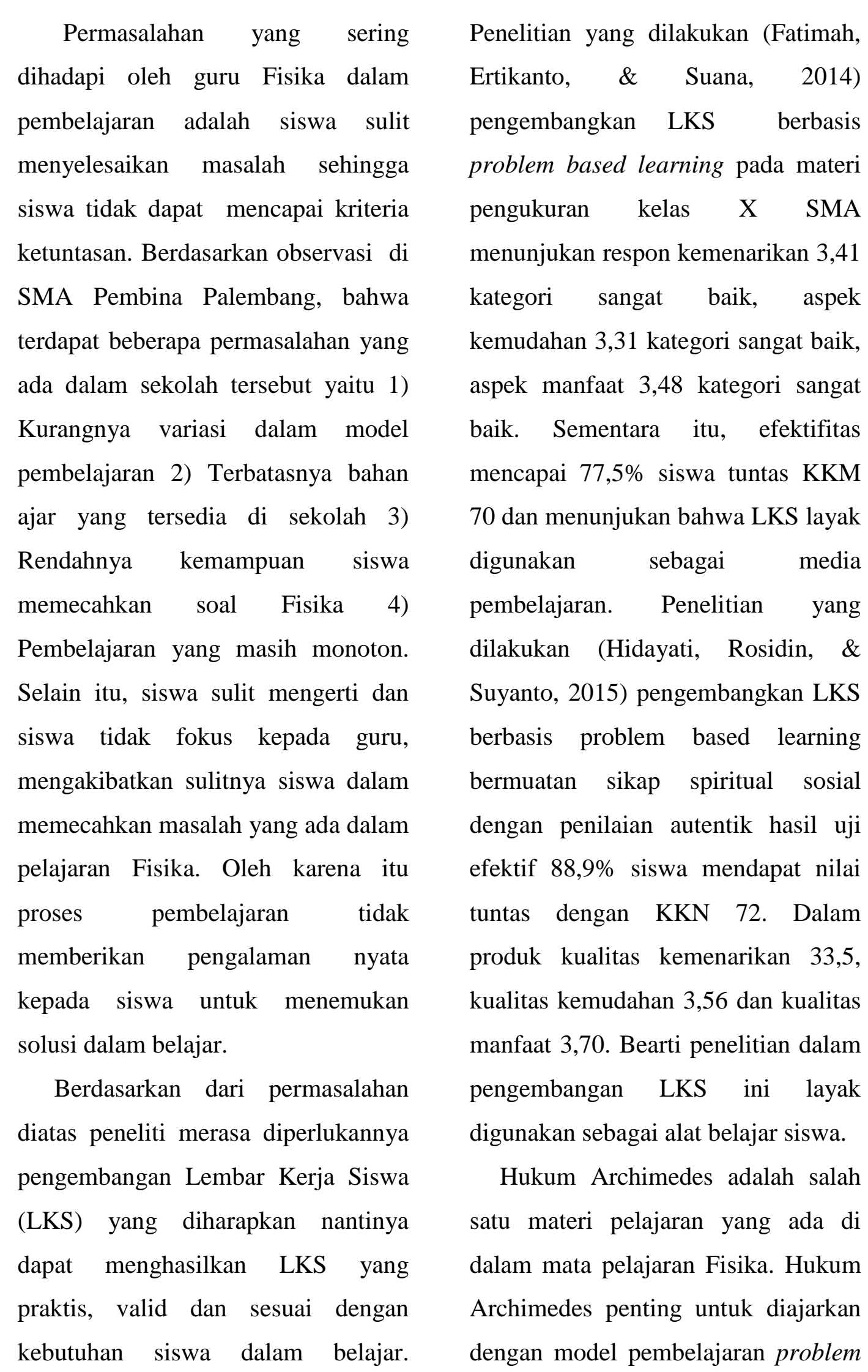


Yuliana., Lubis., Sugiarti. - Pengembangan Lembar Kerja Siswa ...

based learning yaitu: (1) materi Hukum Archimedes merupakan materi yang terbilang sulit dipelajari siswa; (2) materi ini sering dijumpai dalam kehidupan sehari-hari; (3) materi Hukum Archimedes merupakan salah satu materi yang terbilang abstrak bagi siswa. Berdasarkan permasalah yang ada pada siswa menunjukkan adanya kesulitan dalam menyelesaikan masalah. Pengembangan LKS dengan menggunakan model problem based learning diharapkan dapat memberikan dampak yang positif dan bermanfaat bagi guru dan siswa dalam memecahkan masalah.

Model pembelajaran problem based learning adalah model pembelajaran yang menggunakan masalah yang berkaitan dengan kehidupan nyata dalam menerapkan pengetahuan dan untuk menemukan solusi dalam memyelesaikan masalah (Nurqomariah, Gunawan, \& Sutrio, 2015). Model pembelajaran problem based learning adalah model pembelajaran yang menyajikan permasalahan agar siswa dapat merangsang dalam proses belajar melalui pengetahuan yang berkaitan dengan masalah fisika (Yoesoef, 2015). Problem based learning merupakan model belajar yang menggunakan masalah untuk dipecahkan sebagai langkah awal untuk mengumpulkan dan menemukan pengetahuan baru dalam belajar baik induvidu mapun berkalaborasi (Fatimah, Ertikanto, \& Suana, 2014). Problem based learning merupakan model yang menggunakan masalah yang sering dijumpai dikehidupan nyata untuk mendapatkan pengetahuan (Khairunnisa, Yusrizal, \& Halim, 2016). Problem Based Learning adalah aktivitas pembelajaran yang dilakukan siswa untuk melatih mental dan memahami masalah yang disajikan untuk melatih siswa untuk menyelasaikan masalah yang ada dengan menggunakan pendekatan masalah (Utomo, Wahyuni, \& Hariyadi, 2014). Problem Based Learning adalah pembelajaran yang tertuju kepada siswa agar dapat memecahkan suatu masalah memfokuskan siswa agar lebih aktif dalam proses belajar mengajar dan mendorong siswa untuk lebih kreatif dalam memecahkan permasalahan 
Yuliana., Lubis., Sugiarti. - Pengembangan Lembar Kerja Siswa ...

(Tania, Rachman, \& Sugiarti, 2017).

Problem Based Learning adalah model pembelajaran yang melatih mahasiswa agar dapat melatih dalam menggunakan berbagai konsep, prinsip dan keterampilan dalam memecahkan masalah (Fakhriyah, 2014). Problem Based Learning suatu model pembelajaran yang melibatkan siswa untuk memecahkan masalah melalui metode ilmiah sehingga siswa dapat mempelajari pengetahuan dengan suatu masalah sehingga siswa memiliki keterampilan untuk memecahkan masalah (Rerung, Sinon, \& Widyaningsih, 2017).

\section{METODE}

Prosedur penelitian ini menggunakan model pengembangan Rowntree yang terdiri dari 3 tahapan yang terdiri dari tahap perencanaan, tahap pengembangan, dan evaluasi.

\section{Tahap Perencanaan}

Pada tahap perencanaan peneliti mengawalinya dengan melakukan analisis kebutuhan, yaitu mengkaji teori-teori yang berkaitan dengan pengembangan LKS, dengan mencari refrensi hasil penelitian yang relevan seperti jurnal, skripsi dan buku.
Selanjutnya peneliti melakukan analisis kebutuhan yang bertujuan untuk menetapkan kompetensi untuk menghasilkan produk LKS yang akan dikembangkan sesuai dengan karakteristik siswa, seperti menganalisis kurikulum, menentukan Kompetensi Dasar (KD) yang digunakan, tujuan,Iindikator, dan merancang Rencana Pelaksanaan Pembelajaran (RPP) serta merancang instrumen penilaian seperti angket. Instrumen penilaian LKS dikembangkan untuk menilai validasi dan kepraktisan LKS.

\section{Tahap Pengembangan}

Pada tahap pengembangan peneliti akan mendesain LKS, menyusun draf pengembangan dan produksi prototife. Tahap pengembangan topik, merupakan penetuan materi pembelajaran. Materi harus sesuai dengan karakteristik siswa, karakteristik siswa diharapkan dikuasai oleh siswa tersebut setelah mempelajari LKS. Pada tahap menyusun draf peneliti terlebih dahulu menentukan urutan pembelajaran, menentukan materi yang berkaitan dengan materi yang akan dibuat. Setelah menulis materi, 
Yuliana., Lubis., Sugiarti. - Pengembangan Lembar Kerja Siswa ...

dalam penyusunan draf akan Berdasarkan observasi di SMA dipertimbangkan seperti apa yang Pembina Palembang terdapat akan memberikan stimulus yang permasalahan yang ada yaitu optimal bagi siswa. Terakhir produksi kurangnya variasi dalam model prototype yaitu tahap terakhir yang pembelajaran, terbatasnya bahan ajar dilakukan setelah penyusunan draf, yang ada, rendahnya kemampuan karena tahap ini akan disusun dan siswa dalam memecahkan soal Fisika, dilengkapi dengan sunting untuk dan pembelajaran yang masih mendapatkan yang sesuai dengan perencanaan. Hasil dari keseluruhan dalam pengembangan ini disebut prototype pertama.

\section{Evaluasi}

Pada tahap evaluasi peneliti menggunakan evaluasi formatif. Teknik pengumpulan data dengan melakukan observasi, melakukan wawancara, memberi angket (Sugiyono, 2014). Teknik pengumpulan data pada penelitian ini terdiri atas Walkthrough, wawancara, dan angket.

\section{HASIL DAN PEMBAHASAN}

\section{Perencanaan}

Penelitian yang dilakukan oleh peneliti adalah pengembangan Lembar kerja Siswa (LKS) berbasis problem based learning pada pembelajaran Fisika kelas XI IPA di SMA Pembina Palembang. monoton.

\section{Pengembangan}

Tahap awal pengembangan adalah pengembangan dan penyusunan Lembar Kerja Siswa (LKS) yang disusun masuk dalam tahap self evaluation untuk menilai sendiri produk Lembar Kerja Siswa (LKS). Pada tahap expert riview (validasi ahli) dilakukan proses validasi ke dosen Fisika dan Guru SMA. Para validator memberikan penilaian terhadap Lembar Kerja Siswa (LKS) berbasis problem based learning yang dibuat dan Lembar Kerja Siswa (LKS) dinilai dari tiga aspek yaitu aspek materi, aspek desain pembelajaran, dan aspek bahasa.

\section{Evaluasi}

Setelah melakukan validasi kepada validator, nilai rata-rata dari aspek materi 4,38, nilai rata-rata pada 
Yuliana., Lubis., Sugiarti. - Pengembangan Lembar Kerja Siswa ...

aspek desain 4,39, dan nilai rata-rata dari aspek bahasa 4,36 maka nilai total kevalidan Lembar Kerja Siswa (LKS) dari ketiga aspek adalah 4,38 yang artinya Lembar Kerja Siswa berbasis problem based learning yang telah dikembangan pada siswa kelas XI IPA di SMA Pembina Palembang termasuk kategori sangat valid. Hal ini menandakan bahwa Lembar Kerja Siswa (LKS) sudah mencapai tujuan kompetensi yang sudah dirumuskan. Pada produk Lembar Kerja Siswa (LKS) diawali dengan menganalisis kebutuhan siswa seperti kurikulim dan karakteristik pada siswa, selanjutnya peneliti masuk ketahap pengembangan atau prototype 1 yang akan dievaluasi oleh peneliti, kemudian ketahap one to one dan tahap small groub.

Berdasarkan saran dari validator dan komentar dari siswa pada tahap one to one, kemudian dihasilkan prototype 2 yang diujicobakan ke tahap small groub yang berjumlah sepuluh orang siswa kelas XI IPA 2 di SMA Pembina Palembang. Pada tahap ini peneliti memberikan angket kepada siswa untuk mengetahui keperaktisan Lembar Kerja Siswa
(LKS), dari data tahap small groub dihasilkan 22,59 siswa menyatakan Lembar Kerja Siswa (LKS) berbasis problem based learning yang sangat praktis untuk digunakan.

LKS berbasis problem based learning yang dikembangkan memiliki komponen yang meliputi judul, materi, alat dan bahan, langkah-langkah percobaan dan kesimpulan, serta langkah terakhir dalam tahap ini peneliti mencetak LKS.

Berdasarkan hasil lembar validasi ahli, penilaian validator dapat dilihat dari penilaian angket yang diberikan. Langkah ini dilakukan untuk menentukan nilai rata-rata dengan jumlah penelitian terhadap masingmasing kisi-kisi yang dinilai dengan menggunakan skala likert. Hasil penelitian pengolahan data tersebut dapat dilihat pada gambar 1 .

Berdasarkan gambar 1 diperoleh nilai rata-rata hasil penilaian dari kedua validator untuk aspek materi yaitu 4,38, aspek desain pembelajaran problem based learning 4,39, dan aspek bahasa yaitu 4,36. Sehingga LKS berbasis problem based learning dikategorikan Sangat Valid dengan 
Yuliana., Lubis., Sugiarti. - Pengembangan Lembar Kerja Siswa ...

jumlah rata-rata 4,38. Dengan oleh peneliti layak untuk diuji demikian, LKS berbasis problem cobakan dengan revisi sesuai saran. based learning yang dikembangkan

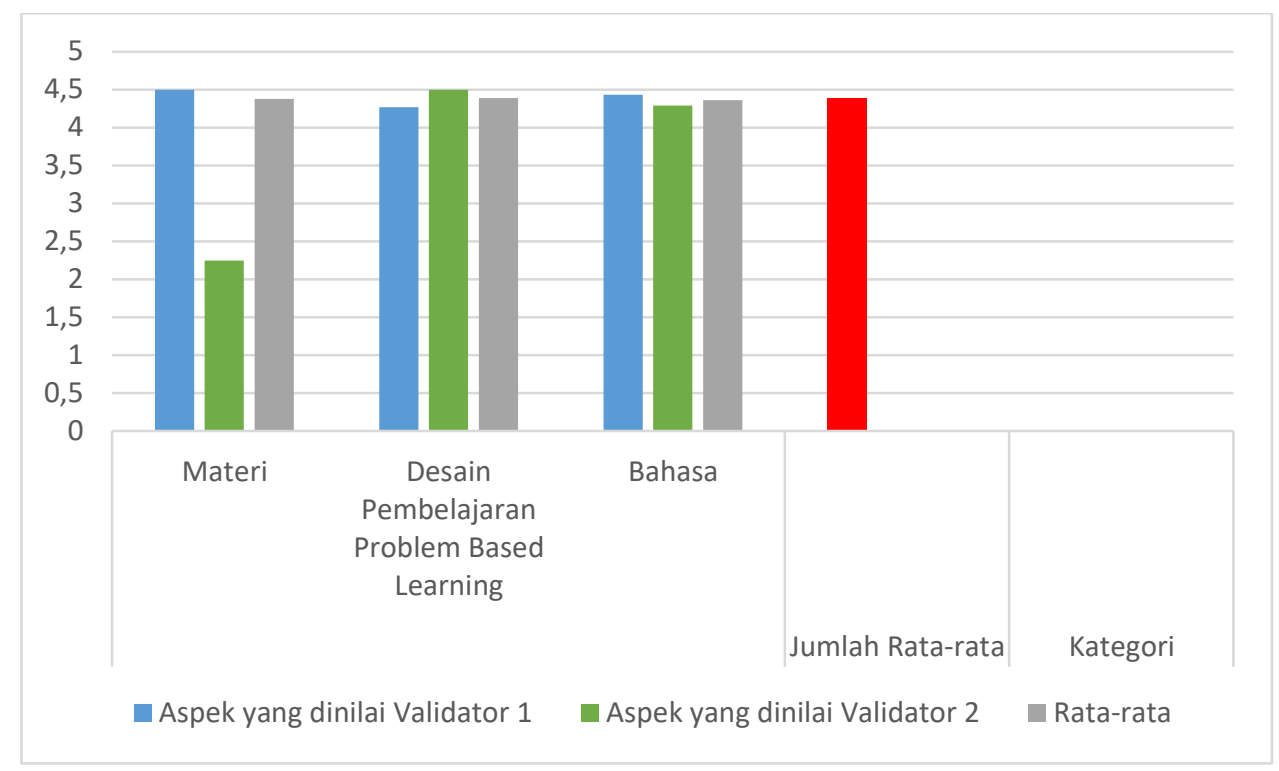

Gambar 1. Rekapitulasi Hasil Penilaian Validator

Walaupun hasil prototype 1 menyatakan sangat valid namun ada komentar dan saran untuk memperbaiki LKS berbasis problem based learning yang dikembangkan.

Hasil pengembangan LKS ini sesuai dengan penelitian tentang Pengembangan Lembar Kerja Siswa (LKS) Berbasis Problem Based Learning. Berdasarkan hasil penelitian diketahui bahwa LKS berbasis PBL dalam pembelajaran baik untuk digunakan dalam pembelajaran (Relawati, 2016; Arifin, 2018)

\section{KESIMPULAN DAN SARAN}

Pada penelitian ini telah mengahasilkan produk Lembar Kerja Siswa (LKS) menggunakan model pembelajaran problem based learning pada materi hukum Archimedes siswa kelas XI SMA Pembina Palembang dapat disimpulkan sebagai berikut:

1. Lembar Kerja Siswa (LKS) yang dikembangkan dalam penelitian ini dikategorikan Sangat Valid. Dikategorikan sangat valid dilihat dari penilaian validator, dengan melalui beberapa aspek yaitu aspek materi rata-rata 4,38 , aspek desain 
Yuliana., Lubis., Sugiarti. - Pengembangan Lembar Kerja Siswa ...

pembelajaran rat-rata 4,39 , dan aspek bahas rata-rata 4,36. Adapun Jumlah rata-rata total kevalidan Lembar Kerja Siswa dari ketiga aspek tersebut yaitu 4,38 yang berarti memenuhi syarat kategori valid. Selain itu validator juga menyatakan bahwa produk Lembar Kerja Siswa (LKS) yang dibuat dapat diuji cobakan.

2. Menurut siswa Lembar Kerja Siswa (LKS) menggunakan model pembelajaran problem based learning pada materi hukum Archimedes dalam pembelajaran Fisika di kelas XI IPA SMA Pembina Palembang sudah termasuk dalam kategori sangat praktis untuk digunakan. Dikategorikan sangat praktis karena dilihat dari jumlah rata-rata angket siswa tahap small group dengan nilai 22,59 yang berarti memenuhi kategori sangat praktis.

Berdasarkan hasil penelitian, peneliti dapat menyarankan hal-hal sebagai berikut:

1. Bagi Guru, sebagai media pembelajaran untuk membantu guru dalam proses belajar mengajar sehingga, guru tidak lagi kesulitan untuk menyiapkan materi pembelajaran dan guru diharapkan dapat mengembangkan media pembelajaran yang lebih interaktif dan sesuai dengan kebutuhan siswa.

2. Bagi Siswa, dapat meningkatkan kemampuan dalam belajar, memberikan pengalaman belajar yang konkret langsung terhadap siswa dan sebagai bahan acuan untuk memudahkan siswa dalam proses belajar.

3. Bagi Penulis, pengembangan Lembar Kerja Siswa (LKS) dapat bermanfaat dalam khasnah ilmu pengetahuan dan sarana untuk mengembangkan kemampuan penulis dalam mengembangkan Lembar Kerja Siswa khususnya menggunakan model pembelajaran Problem Based Learning.

\section{DAFTAR PUSTAKA}

Arifin, Z. (2012). Evaluasi Pembelajaran. Jakarta: Direktorat Jendral Pendidikan Islam Kementrian Agama RI.

Fakhriyah, F. (2014). Penerapan problem based learning dalam upaya mengembangkan kemampuan berpikir kritis mahasiswa. Jurnal Pendidikan IPA Indonesia, 3(1). 
Yuliana., Lubis., Sugiarti. - Pengembangan Lembar Kerja Siswa ...

Fatimah, S., Ertikanto, C., \& Suana, W. (2014). Pengembangan LKS berbasis problem based learningmateri pengukuran kelas $\mathrm{X}$ SMA. Jurnal Pembelajaran Fisika, 2(6).

Hidayati, A., Rosidin, U., \& Suyanto, E. (2015). Pengembangan Lks Problem Based Learning Bermuatan Sikap Spiritual Sosial Dengan Penilaian Autentik. Jurnal Pembelajaran Fisika, 3(2).

Khairunnisa, Yusrizal, \&Halim, A. (2016). Pengembangan Lks Berbasis Problem Based Learning Bermuatan Sikap Spiritual pada Materi Pengukuran untuk Meningkatkan Kemampuan Berpikir Kritis Siswa. Jurnal Ilmiah Mahasiswa Pendidikan Fisika, 1(4), 284-291.

Nurqomariah, N., Gunawan, G., \& Sutrio, S. (2017). Pengaruh Model Problem Based Learning dengan Metode Eksperimen Terhadap Hasil Belajar IPA Fisika Siswa Kelas VII SMP Negeri 19 Mataram Tahun Pelajaran 2014/2015. Jurnal Pendidikan Fisika dan Teknologi, 1(3), 173179.

Purwanto, A. (2012). Kemampuan berpikir logis siswa SMA Negeri 8 kota Bengkulu dengan menerapkan model inkuiri terbimbing dalam pembelajaran fisika. EXACTA, 10(2), 133-135.
Relawati. (2016). Pengembangan Lembar Kerja Siswa (Lks) Berbasis Problem Based Learning Pada Materi Bilangan Di Kelas VII SMP Negeri 22 Kota Jambi. Jurnal Ilmiah Dikdaya, 6(1).

Rerung, N., Sinon, I. L., \& Widyaningsih, S. W. (2017). Penerapan model pembelajaran problem based learning (PBL) untuk meningkatkan hasil belajar peserta didik SMA pada materi usaha dan energi. Jurnal Ilmiah Pendidikan Fisika Al-Biruni, 6(1), 47-55.

Ruman, Kurniawan, D., \& Riyana, C. (2012). Pembelajaran Berbasis Teknologi Informasi dan Komunikasi. Jakarta: PT RajaGrafindo Persada.

Sugiyono. (2014). Cara Mudah Menyusun Skripsi, Tesis, dan Disertasi . Bandung: Alfabeta.

Tania, R., Rachman, F. A., \& Sugiarti, S. (2017, October). Pengaruh Model Pembelajaran Problem Based Learning (PBL) Terhadap Kemampuan Pemahaman Konsep Pada Mata Pelajaran Fisika Kelas X SMA Negeri 1 Tempilang Kabupaten Bangka Barat. In Seminar Nasional Pendidikan IPA (Vol. 1, No. 1, pp. 45-51).

Utomo, T., Wahyuni, D., \& Hariyadi, S. (2014). Pengaruh Model Pembelajaran Berbasis Masalah (Problem Based Learning) Terhadap Pemahaman Konsep dan 
Yuliana., Lubis., Sugiarti. - Pengembangan Lembar Kerja Siswa ...

Kemampuan Berpikir Kreatif

Siswa (Siswa Kelas VIII Semester

Gasal SMPN 1 Sumbermalang

Kabupaten Situbondo Tahun

Ajaran 2012/2013). Jurnal

Edukasi, 1(1), 5-9.

Yoesoef, A. (2015). Penerapan Model

Problem Based Learning Untuk

Meningkatkan Kemampuan

Menanya Dan Penguasaan Konsep

Fisika Kelas X MIA 1 SMA

Negeri 2 Kediri. PINUS: Jurnal

Penelitian Inovasi Pembelajaran, 1(2)

Yolanda, D. T., Lubis, P., \& Sugiarti.

(2020). Pengaruh Model
Pembelajaran Contextual Teaching (CTL) Berbantual Alat Peraga Terhadap Pemahaman Konsep Fisika Siswa SMA. Jurnal Luminous, 1(1).

Yunita, L. (2016). Efektifitas Problem Based Learning Berbantuan Edmodo Untuk Meningkatkan Prestasi Belajar Fisika Studi Pada Suhu dan Kalor Kelas X Teknik Kendaraan Ringan SMK Tunas Bangsa Wanareja. Prosiding Seminar National ReTII ke-11 2016, 159. 